\title{
PELATIHAN MELALUI WEB SEMINAR TERKAIT PENULISAN ARTIKEL BERBASIS BIBLIOGRAPHICAL RESEARCH METHOD DALAM BIDANG AKUNTANSI UNTUK PUBLIKASI PADA JURNAL INTERNASIONAL BEREPUTASI
}

\author{
TRAINING THROUGH WEB SEMINAR RELATED TO \\ BIBLIOGRAPHICAL RESEARCH METHOD BASED ARTICLES IN \\ ACCOUNTING FOR PUBLICATION IN THE REPUTABLE \\ INTERNATIONAL JOURNAL
}

\author{
Amrie Firmansyah $^{1 *)}$, Amardianto Arham ${ }^{2)}$, Resi Ariyasa Qadri ${ }^{3)}$ \\ 1,3,3 Jurusan Akuntansi, Politeknik Keuangan Negara STAN \\ ${ }^{1)}$ Email : amrie.firmansyah@gmail.com
}

\begin{abstract}
Abstrak : Kegiatan pengabdian kepada masyarakat ini bertujuan untuk memberikan pelatihan bagi dosen, mahasiswa, dan para peneliti mengenai penulisan artikel jurnal dengan basis bibliographical research method sebagai salah satu alternatif untuk mempublikasikan artikel penelitian dalam kondisi pandemi Covid-19. Adanya kewajiban bagi dosen dan mahasiswa untuk melakukan publikasi artikel penelitian memerlukan suatu metode penelitian alternatif yang memungkinkan untuk digunakan dalam kondisi work from home. Pelatihan ini dilaksanakan melalui web seminar karena adanya kondisi pandemi Covid-19 yang tidak memungkinkan untuk memberikan pelatihan secara konvensional. Penyelenggara kegiatan ini adalah Universitas Pamulang di Tangerang Selatan, Banten. Kegiatan ini diikuti oleh dosen dan mahasiswa yang tidak hanya berasal dari Pulau Jawa tetapi juga dari luar Pulau Jawa. Metode pelaksanaan kegiatan pengabdian kepada masyarakat ini terdiri atas beberapa tahap. Tahap pertama adalah tahap perencanaan melalui diskusi dengan perwakilan kampus penyelenggara, penyusunan materi, serta diskusi internal tim seputar materi. Tahap kedua adalah pemaparan materi dan diskusi melalui web seminar yang dilakukan dengan aplikasi Google Meet. Tahap ketiga adalah diskusi lebih lanjut secara online dengan pesertapeserta yang membutuhkan penjelasan tambahan mengenai materi yang telah disampaikan. Berdasarkan hasil diskusi dan feedback yang diperoleh dari para peserta, beberapa peserta kegiatan termotivasi untuk melakukan penelitian dengan menggunakan bibliographical research method khususnya dosen yang memiliki kewajiban untuk mempublikasikan hasil penelitian pada jurnal ilmiah.
\end{abstract}

Kata Kunci: artikel, bibliografi, jurnal, publikasi

Abstract : This community service activity aims to provide training for lecturers, students, and researchers on writing journal articles on the basis of the bibliographical research method as an alternative to publish research articles in the Covid-19 pandemic conditions. The obligation for lecturers and students to publish research articles requires an alternative research method that is possible to use in conditions of work from home. This training was carried out through a web seminar due to the condition of the Covid-19 pandemic which made it impossible to provide conventional training. The organizer of this activity is Pamulang University in South Tangerang, Banten. This activity was attended by lecturers and students who were not only from Java but also from outside 


\section{INTEGRITAS : Jurnal Pengabdian}

Vol 4, No 1, Juli 2020

ISSN 2580 - 7978 (cetak) ISSN 2615-0794 (online)

Java. The method of carrying out community service activities consists of several stages. The first stage is the planning stage through discussions with the organizers of campus representatives, preparation of material, and internal team discussions aboutthe material. The second stage is the presentation of material and discussion through a web seminar by using the Google Meet application. The third stage is further online discussion with participants who need additional explanation about the material that has been presented. Based on the results of discussions and feedback obtained from the participants, some participants of this activity are motivated to conduct research by using the bibliographical research method especially lecturers who have the obligation to publish research results in scientific journals.

Keywords: article, bibliography, journal, publication

\section{PENDAHULUAN}

Berdasarkan Pasal 1 Undang-Undang Nomor 12 Tahun 2012 tentang Pendidikan Tinggi, seorang dosen memiliki kewajiban untuk melaksanakan tridarma perguruan tinggi yaitu, pendidikan/pengajaran, penelitian, dan pengabdian kepada masyarakat. Dalam pelaksanaan tridarma perguruan tinggi, penelitian memiliki peran yang cukup penting bahkan menjadi salah satu indikator dalam penetapan angka kredit seorang fungsional dosen. Sebagai bentuk pengembangan ilmu pengetahuan, suatu hasil penelitian perlu dituangkan ke dalam sebuah tulisan (Gunawan, 2014). Tulisan yang dimaksud dalam hal ini adalah artikel ilmiah.

Kondisi pandemi Covid-19 menyebabkan timbulnya keterbatasan bagi dosen, mahasiswa, dan para peneliti untuk melakukan penelitian dan menghasilkan artikel ilmiah. Akan tetapi, mengingat adanya kewajiban bagi dosen dan mahasiswa untuk melakukan publikasi artikel penelitian, maka diperlukan suatu metode penelitian alternatif yang memungkinkan untuk digunakan dalam kondisi work from home akibat pandemi Covid-19.

Villas et al. (2008) memberikan salah satu metode penelitian alternatif dalam penulisan artikel ilmiah di bidang akuntansi yaitu metode penelitian berbasis bibliografi (bibliographical research method). Pendekatan bibliografi adalah penelitian yang dilakukan dengan menganalisis suatu topik berdasarkan suatu sudut pandang dengan menggunakan publikasi ilmiah (artikel jurnal, 


\section{INTEGRITAS : Jurnal Pengabdian}

Vol 4, No 1, Juli 2020

ISSN 2580-7978 (cetak) ISSN 2615-0794 (online)

prosiding, buku, dan lain-lain) sebagai bahan analisis (Villas et al., 2008). Dengan demikian, pendekatan ini dapat dijadikan sebagai salah satu alternatif untuk mempublikasikan artikel penelitian di tengah kondisi pandemi Covid-19. Keunggulan dari pendekatan bibliografi ini adalah tidak perlu untuk melakukan aktivitas penelitian di luar rumah. Hal tersebut tentu sejalan dengan imbauan pemerintah agar masyarakat selalu tetap berada di rumah (stay at home) selama kondisi pandemi Covid-19.

Metode penelitian bibliografi bertujuan untuk mengetahui perkembangan penelitian pada topik tertentu sehingga dapat menemukan kesenjangan penelitian (Villas et al., 2008). Penelitian bibliografi sudah cukup banyak dilakukan dan telah dipublikasikan pada jurnal internasional bereputasi yang biasa disebut sebagai jurnal terindeks Scopus. Penelitian-penelitian tersebut telah mengulas beberapa topik antara lain, manajemen strategi (Zoogah \& Rigg, 2014), penelitian akuntansi (Merigó \& Yang, 2016), other comprehensive income (Black, 2016), penelitian akuntansi digital (Ardianto \& Anridho, 2018), penelitan modal ventura (Cancino et al., 2018), sistem informasi akuntansi (Chiu et al., 2018; Ezenwoker et al., 2019), akuntansi sektor publik (Fusco \& Ricci, 2018), kualitas pelaporan keuangan (Riyard et al., 2019), audit internal (Behrend \& Eulerich, 2019), adopsi IFRS (Arham et al., 2020a), akuntansi manajemen (Balstard \& Berg, 2020), serta tax avoidance (Arham et al., 2020b).

Seorang dosen atau peneliti yang memiliki publikasi di jurnal-jurnal internasional bereputasi dapat dikatakan telah memiliki kompetensi yang baik dalam hal penelitian. Akan tetapi, publikasi penelitan pada jurnal internasional bereputasi bukanlah hal yang mudah bagi seorang dosen atau peneliti. Banyak peneliti yang mengalami kesulitan untuk menulis artikel ilmiah dan kurang mendapatkan pelatihan terkait penulisan artikel hasil penelitian (Ecarnot et al., 2015). Selain itu, adanya ketentuan-ketentuan yang harus dipenuhi secara umum dalam penulisan artikel pada jurnal internasional bereputasi mengakibatkan proses publikasi menemui hambatan. 


\section{INTEGRITAS : Jurnal Pengabdian}

Vol 4, No 1, Juli 2020

ISSN 2580 - 7978 (cetak) ISSN 2615-0794 (online)

Peraturan Menteri Riset, Teknologi, dan Pendidikan Tinggi Republik Indonesia Nomor 44 Tahun 2015 tentang Standar Nasional Pendidikan Tinggi menjabarkan tentang standar hasil penelitan, standar peneliti, serta standar pendanaan dan pembiayaan penelitian. Peraturan tersebut mengharuskan suatu hasil penelitian memenuhi kaidah dan metode ilmiah secara sistematis. Kompetensi untuk memahami, mensintesis, dan mengevaluasi suatu hal merupakan hal penting dalam pengembangan karier di berbagai disiplin ilmu (Gilinsky Jr et al., 2016). Sebagai seorang peneliti, dosen wajib memahami metodologi penelitian dengan baik. Di samping itu, kompetensi menulis adalah salah satu wujud pengembangan diri agar mampu meraih karier profesional yang sukses (Ortinau, 2011).

Permasalahan yang kemudian timbul adalah belum semua dosen, mahasiswa, atau peneliti terampil dan terlatih dalam penulisan artikel jurnal internasional terutama yang menggunakan bibliographical research method. Oleh karena itu, upaya peningkatan kemampuan dosen, mahasiswa, dan peneliti dalam hal penulisan artikel jurnal internasional yang berbasis bibliographical research method perlu dilakukan. Upaya tersebut dapat dilakukan melalui suatu kegiatan pengabdian kepada masyarakat dalam bentuk pendampingan penulisan artikel ilmiah. Kegiatan pengabdian masyarakat dalam bentuk pendampingan penulisan artikel ilmiah sudah cukup banyak dilakukan, antara lain bagi guru Sekolah Dasar (Ilfiandra et al., 2016), guru Sekolah Menengah Pertama (Gunawan et al., 2018; Prabawati \& Muslim, 2020), guru Madrasah Aliyah (Muhali et al., 2019), dan mahasiswa (Sukardi et al., 2019). Akan tetapi, kegiatan pendampingan penulisan artikel yang khusus ditujukan bagi dosen dan mahasiswa masih sangat jarang dilakukan. Selain itu, pendampingan penulisan artikel yang khusus membahas mengenai bibliographical research method masih sangat jarang dilakukan. Oleh karena itu, kegiatan ini perlu dilakukan agar dapat memberikan kesempatan bagi dosen dan mahasiswa untuk tetap dapat melakukan penelitian dan mempublikasikan hasil penelitian pada jurnal internasional bereputasi meskipun 


\section{INTEGRITAS : Jurnal Pengabdian}

Vol 4, No 1, Juli 2020

ISSN 2580-7978 (cetak) ISSN 2615-0794 (online)

adanya berbagai keterbatasan dalam kondisi pandemi Covid-19. Dengan adanya kegiatan ini, dosen dan pihak-pihak yang melakukan penelitian diharapkan dapat termotivasi untuk tetap bisa produktif di masa pandemi Covid-19 dengan menghasilkan artikel penelitian berbasis bibliographical research method dan mempublikasikan hasil penelitian pada jurnal internasional bereputasi.

Kegiatan pengabdian kepada masyarakat dalam bentuk Pelatihan melalui Web Seminar terkait Penulisan Artikel Berbasis Bibliographical Research Method dalam Bidang Akuntansi untuk Publikasi pada Jurnal Internasional Bereputasi bertujuan untuk memberikan pelatihan bagi dosen, mahasiswa, dan para peneliti mengenai penulisan artikel jurnal dengan basis bibliographical research method sebagai salah satu alternatif untuk mempublikasikan artikel penelitian dalam kondisi pandemi Covid-19. Kegiatan ini diharapkan dapat membangkitkan motivasi dan produktivitas publikasi ilmiah serta memberikan tips dan trik dalam menghasilkan artikel berbasis bibliographical research method yang dapat menembus publikasi pada jurnal internasional bereputasi. Di tengah kondisi pandemi Covid-19 yang tidak memungkinkan untuk melakukan kegiatan secara tatap muka, kegiatan ini dilaksanakan melalui Web Seminar dengan bantuan aplikasi Google Meet. Kegiatan ini diselenggarakan oleh Universitas Pamulang di Tangerang Selatan, Banten. Adapun peserta kegiatan ini adalah dosen dan mahasiswa yang tidak hanya berasal dari Pulau Jawa tetapi juga dari luar Pulau Jawa.

\section{METODE PELAKSANAAN}

Metode pelaksanaan kegiatan pengabdian kepada masyarakat ini dibagi menjadi beberapa tahap. Tahap pertama yaitu tahap perencanaan. Pada tahap ini, Tim dan pihak penyelenggara mendiskusikan dan mengidentifikasi masalah beserta output yang diharapkan oleh para peserta Web Seminar. Kegiatan ini dilakukan untuk dapat merencanakan dan mempersiapkan materi yang akan 


\section{INTEGRITAS : Jurnal Pengabdian}

Vol 4, No 1, Juli 2020

ISSN 2580 - 7978 (cetak) ISSN 2615-0794 (online)

disampaikan dalam Web Seminar. Selain itu, Tim melakukan diskusi internal terkait materi yang akan disampaikan dalam Web Seminar.

Tahap kedua dalam kegiatan pengabdian kepada masyarakat ini yaitu pelaksanaan kegiatan. Kegiatan ini dilaksanakan dalam bentuk penyampaian materi oleh salah satu anggota Tim. Adapun materi-materi yang disampaikan yaitu latar belakang atau konsep, langkah-langkah yang harus dilakukan oleh peneliti, serta kiat-kiat agar penelitian berbasis bibliographical research method dapat dipublikasikan pada jurnal internasional bereputasi.

Tahap terakhir dalam kegiatan pengabdian kepada masyarakat ini yaitu tidak lanjut atas pelaksanaan kegiatan. Tahap ini dilakukan dengan menjawab pertanyaan-pertanyaan yang diberikan oleh peserta setelah berakhirnya kegiatan. Kegiatan ini dilakukan melalui diskusi lebih lanjut secara online dengan pesertapeserta yang membutuhkan penjelasan tambahan terkait materi yang telah disampaikan.

Target yang ingin dicapai dalam kegiatan pengabdian kepada masyarakat ini adalah para dosen dan semua pihak yang melakukan penelitian dapat memiliki motivasi yang tinggi untuk melakukan penelitian dan mempublikasikan artikel hasil penelitian berbasis bibliographical research method pada jurnal internasional bereputasi.

\section{HASIL DAN PEMBAHASAN}

Kegiatan pengabdian kepada masyarakat ini dilaksanakan pada Selasa, 19 Mei 2020, pukul 15.30-17.30 WIB, di Universitas Pamulang, Tangerang Selatan, Banten, dengan menggunakan aplikasi Google Meet. Kegiatan ini diikuti oleh sebanyak 120 orang peserta. Peserta kegiatan ini merupakan dosen, mahasiswa, dan peneliti yang tidak hanya berasal dari Pulau Jawa tetapi juga dari luar Pulau Jawa.

Pada tahap pelaksanaan kegiatan, dua orang perwakilan Tim bertugas sebagai pemateri. Hal-hal yang disampaikan yaitu mengenai latar belakang 


\section{INTEGRITAS : Jurnal Pengabdian}

Vol 4, No 1, Juli 2020

ISSN 2580-7978 (cetak) ISSN 2615-0794 (online)

sejarah penelitian berbasis bibliographical research method, tujuan penelitian bibliografi, area riset bibliografi dalam bidang akuntansi, contoh penelitian bibliografi, serta proses penelitian bibliografi yang meliputi teknis pengumpulan data, pengolahan data, hingga pengambilan kesimpulan.

Pemaparan diawali dengan penyampaian materi mengenai latar belakang sejarah penelitian bibliografi sebagaimana dijelaskan dalam artikel Villas et al. (2008), yang dimulai dari literature review, survey, kemudian bibliographical research method. Tim melanjutkan pemaparan dengan menjelaskan tujuan penelitian bibliografi yaitu untuk mengetahui perkembangan penelitian pada topik tertentu sehingga dapat menemukan kesenjangan penelitian.

Selanjutnya, Tim menyampaikan topik-topik yang dapat menjadi area riset berbasis bibliografi dalam bidang akuntansi, antara lain, akuntansi keuangan berbasis pasar modal, akuntansi manajemen, perpajakan (penghindaran pajak, transfer pricing, kepatuhan pajak), pelaporan keuangan, sistem informasi akuntansi, audit eksternal, audit internal, CSR disclosure, good governance, pengendalian internal, serta proses perencanaan dan penganggaran. Tim juga menampilkan contoh-contoh penelitian bibliografi dalam bidang akuntansi yang telah dipublikasikan pada jurnal internasional bereputasi.

Tim melanjutkan pemaparan terkait proses penelitian bibliografi. Pemaparan diawali dengan penjelasan terkait teknis pengumpulan data. Tim menyampaikan bahwa pengumpulan data diawali dengan mencari berbagai artikel jurnal melalui laman Google Scholar dengan menggunakan kata kunci tertentu dalam bahasa Indonesia \& bahasa Inggris. Tim juga menerangkan bahwa artikel yang dikumpulkan hanyalah artikel dari jurnal yang telah terakreditasi Sinta atau terindeks Scopus dengan mengecek akreditasi jurnal melalui situs http://sinta.ristekbrin.go.id/journals (jurnal Indonesia) dan https://www.scimagojr.com (jurnal internasional). Tim kemudian menampilkan langkah-langkah untuk mengecek akreditasi jurnal Indonesia maupun jurnal internasional. 


\section{INTEGRITAS : Jurnal Pengabdian}

Vol 4, No 1, Juli 2020

ISSN $2580-7978$ (cetak) ISSN 2615 - 0794 (online)

Setelah itu, Tim menjelaskan teknis pengolahan data. Tim menyampaikan bahwa pengolahan data penelitian bibliografi dapat menggunakan aplikasi Microsoft Excel yang diawali dengan memasukkan data dari artikel jurnal yang telah dikumpulkan ke dalam tabel yang menjadi database. Tim menguraikan data apa saja yang dimasukkan ke dalam database meliputi, nama file, tahun, nama peneliti, penerbit, tingkat akreditasi, bahasa, metode penelitian, topik penelitian, teori penelitian, unit analisis, tahun analisis, jumlah tahun analisis, jumlah sampel, variabel idependen, jenis proksi variabel dependen, jumlah variabel independen, variabel independen beserta hasil pengujian, variabel moderasi beserta hasil pengujian, variabel mediasi beserta hasil pengujian, variabel kontrol, serta jenis pendekatan kualitatif. Setelah itu, Tim menambahkan bahwa peserta dapat menggunakan fitur pivot table dalam aplikasi Microsoft Excel untuk memetakan dan mengetahui seberapa banyak suatu item data telah digunakan dalam penelitian untuk selanjutnya dapat disajikan dalam bentuk tabel atau grafik. Agar dapat lebih mudah dipahami oleh peserta, Tim menampilkan dan menjelaskan secara detil dan teknis mengenai contoh-contoh penyajian hasil pemetaan.

Selanjutnya, Tim menyampaikan mengenai teknis pengambilan kesimpulan. Tim menjelaskan bahwa dalam penelitian bibliografi, kesimpulan diambil berdasarkan hasil pengolahan dan analisis data (pemetaan). Tim menguraikan lebih lanjut bahwa kesimpulan dapat berupa dua hal. Pertama, kesimpulan dapat berupa hal apa yang paling banyak digunakan. Terkait hal tersebut, peserta dapat memetakan dan menjabarkan dalam bagian pembahasan. Kedua, kesimpulan dapat berupa hal apa yang masih jarang digunakan. Terkait hal tersebut, Tim menjelaskan bahwa dalam penelitian bibliografi, penulis dapat merekomendasikan suatu hal berdasarkan bukti-bukti empiris yang dapat menjadi saran dan agenda riset di masa depan.

Terakhir, Tim memberikan kesempatan bagi para peserta untuk memberikan pertanyaan. Dengan perantara moderator, para peserta dipersilakan untuk mengajukan beberapa pertanyaan kepada Tim. Karena keterbatasan waktu, 


\section{INTEGRITAS : Jurnal Pengabdian}

Vol 4, No 1, Juli 2020

ISSN 2580-7978 (cetak) ISSN 2615-0794 (online)

tidak semua peserta memperoleh kesempatan untuk bertanya selama kegiatan berlangsung. Akan tetapi, Tim masih memberikan kesempatan bagi para peserta yang masih membutuhkan penjelasan tambahan mengenai materi yang telah disampaikan melalui diskusi secara online setelah acara selesai. Hal ini merupakan tindak lanjut dari pelaksanaan kegiatan pengabdian kepada masyarakat ini.

Di akhir kegiatan ini, para peserta diminta untuk memberikan feedback, masukan, atau saran terkait pelaksanaan kegiatan ini dengan mengisi form secara online. Berdasarkan feedback yang diperoleh dari peserta, kegiatan ini sangat bermanfaat bagi peserta dan memotivasi peserta agar tetap bisa produktif di masa pandemi Covid-19 dengan menghasilkan artikel penelitian berbasis bibliographical research method dan mempublikasikan hasil penelitian pada jurnal internasional bereputasi.

\section{KESIMPULAN}

Kegiatan pengabdian kepada masyarakat ini bertujuan untuk memberikan pelatihan bagi dosen, mahasiswa, dan para peneliti mengenai penulisan artikel jurnal dengan basis bibliographical research method sebagai salah satu alternatif untuk mempublikasikan artikel penelitian dalam kondisi pandemi Covid-19.

Kegiatan pengabdian kepada masyarakat ini dilakukan dalam periode yang relatif singkat dan hanya melalui web seminar sehingga pemahaman yang diperoleh peserta mungkin masih belum optimal. Dengan demikian, kegiatan pengabdian kepada masyarakat lanjutan dapat dilakukan dengan mengundang peserta untuk mengikuti pelatihan secara tatap muka. Selain itu, frekuensi pelatihan dapat ditambah namun dengan jumlah peserta yang lebih sedikit agar dapat memastikan perkembangan dari setiap peserta kegiatan.

Kegiatan pengabdian masyarakat dengan pola pemberian edukasi atau pendampingan kepada dosen atau peneliti yang belum memiliki pengalaman dalam penulisan artikel berbasis bibliographical research method yang 


\section{INTEGRITAS : Jurnal Pengabdian}

Vol 4, No 1, Juli 2020

ISSN 2580-7978 (cetak) ISSN 2615-0794 (online)

dipublikasikan pada jurnal internasional terindeks Scopus perlu dilakukan untuk meningkatkan produktivitas dan kualitas hasil penelitian dosen, mahasiswa, maupun para peneliti. Oleh karena itu, peran serta dosen-dosen yang memiliki pengalaman di bidang tersebut sangat dibutuhkan agar dapat meningkatkan produktivitas dan kualitas dosen, mahasiswa, maupun para peneliti melalui publikasi artikel berbasis bibliographical research method pada jurnal yang bereputasi secara internasional. Dengan demikian, kualitas dosen dan mahasiswa dalam melaksanakan tridarma perguruan tinggi juga dapat meningkat.

\section{DAFTAR PUSTAKA}

Ardianto, A., \& Anridho, N. (2018). Bibliometric analysis of digital accounting research. The International Journal of Digital Accounting Research, 18, 141-159.

Arham, A., Firmansyah, A., Nor, A. M. E., \& Vito, B. (2020a). A Bibliographic Study on IFRS Adoption Research in Indonesia. International Journal of Psychosocial Rehabilitation, 24(7), 9477-9501.

Arham, A., Firmansyah, A., Nor, A. M. E., \& Vito, B. (2020b). A Bibliographic Study on Tax Avoidance Research in Indonesia. International Journal of Psychosocial Rehabilitation, 24(7), 9526-9554.

Balstad, M. T., \& Berg, T. (2020). A long-term bibliometric analysis of journals influencing management accounting and control research. Journal of Management Control, 30(4), 357-380.

Behrend, J., \& Eulerich, M. (2019). The evolution of internal audit research: a bibliometric analysis of published documents (1926-2016). Accounting History Review, 29(1), 103-139.

Black, D. E. (2016). Other comprehensive income: a review and directions for future research. Accounting \& Finance, 56(1), 9-45.

Cancino, C. A., Merigo, J. M., Torres, J. P., \& Diaz, D. (2018). A bibliometric analysis of venture capital research. Journal of Economics, Finance and Administrative Science, 23(45), 182-195.

Chiu, V., Liu, Q., Muehlmann, B., \& Baldwin, A. A. (2019). A bibliometric analysis of accounting information systems journals and their emerging technologies contributions. International Journal of Accounting Information Systems, 32, 24-43.

Ecarnot, F., Seronde, M. F., Chopard, R., Schiele, F., \& Meneveau, N. (2015). Writing a scientific article: A step-by-step guide for beginners. European Geriatric Medicine, 6(6), 573-579. 
Ezenwoke, O. A., Ezenwoke, A., Eluyela, F. D., \& Olusanmi, O. (2019). A Bibliometric Study of Accounting Information Systems Research from 1975-2017. Asian Journal of Scientific Research, 12(2), 167-178.

Fusco, F., \& Ricci, P. (2019). What is the stock of the situation? A bibliometric analysis on social and environmental accounting research in public sector. International Journal of Public Sector Management, 32(1), 21-41.

Gilinsky Jr, A., Forbes, S. L., \& Reed, M. M. (2016). Writing cases to advance wine business research and pedagogy: A Business Article by. Wine Economics and Policy, 5(1), 60-67.

Gunawan, I. (2014). Metode Penelitian Kualitatif: Teori dan Praktik. Jakarta: Bumi Aksara.

Gunawan, I., Triwiyanto, T., \& Kusumaningrum, D. E. (2018). Pendampingan penulisan artikel ilmiah bagi para guru sekolah menengah pertama. Abdimas Pedagogi: Jurnal Ilmiah Pengabdian kepada Masyarakat, 1(2), 128-135.

Ilfiandra, I., Suherman, U., Akhmad, S. N., Budiamin, A., \& Setiawati, S. (2016). Pelatihan dan Pendampingan Penulisan Karya Tulis Ilmiah Bagi Guru SD. Jurnal Pengabdian Pada Masyarakat, 1(1), 70-81.

Merigó, J. M., \& Yang, J. B. (2017). Accounting research: A bibliometric analysis. Australian Accounting Review, 27(1), 71-100.

Muhali, M., Asy'ari, M., Prayogi, S., Samsuri, T., Karmana, I. W., Sukarma, I. K., Mirawati, B., Firdaus, L., \& Hunaepi, H. (2019). Pelatihan Kegiatan Penelitian dan Penulisan Karya Ilmiah bagi Guru Madrasah Aliyah Negeri 3 Lombok Tengah. Abdihaz: Jurnal Ilmiah Pengabdian pada Masyarakat, 1(1), 28-36.

Ortinau, D. J. (2011). Writing and publishing important scientific articles: A reviewer's perspective. Journal of Business Research, 64(2), 150-156.

Peraturan Menteri Riset, Teknologi, dan Pendidikan Tinggi Republik Indonesia Nomor 44 Tahun 2015 tentang Standar Nasional Pendidikan Tinggi.

Prabawati, M. N., \& Muslim, S. R. (2020). Pendampingan Penulisan Artikel Ilmiah Bagi Guru Matematika Sekolah Menengah Pertama Wilayah Sukaraja Kabupaten Tasikmalaya. ABDIMAS: Jurnal Pengabdian Masyarakat, 3(1), 207-212.

Riyard, A. K., Azli, M. N., \& Bosi, M. K. (2019). Scientific Publication Analysis: Financial Reporting Quality Insight. International Journal of Recent Technology and Engineering (IJRTE), 8(4), 3159-3173.

Sukardi, S., Burhanuddin, B., \& Wardana, L. A. (2019). Pelatihan dan Pendampingan Swasunting Artikel Ilmiah untuk Mahasiswa Magister Bidang Pendidikan Pascasarjana Universitas Mataram. Jurnal Pendidikan dan Pengabdian Masyarakat, 2(1), 23-29.

Undang-Undang Nomor 12 Tahun 2012 tentang Pendidikan Tinggi.

Villas, M. V., Macedo-Soares, T. D. L., \& Russo, G. M. (2008). Bibliographical research method for business administration studies: a model based on 


\section{INTEGRITAS : Jurnal Pengabdian}

Vol 4, No 1, Juli 2020

ISSN 2580 - 7978 (cetak) ISSN 2615-0794 (online)

scientific journal ranking. BAR-Brazilian Administration Review, 5(2), 139159.

Zoogah, D.B., \& Rigg, J.S. (2014), Bibliographic Analysis and Strategic Management Research in Africa. Advancing Research Methodology in the African Context: Techniques, Methods, and Designs (Research Methodology in Strategy and Management), 10, 189-213. 